DOI: $10.5937 /$ halo26-27845

UDC: $616.888 .1-053.6$

Savić N, i sar.

Adolescencija i

kontracepcija. Halo 194.

2020; 26(3):126-132.

Rad primljen: 07.08.2020

Prihvaćen: $\quad 08.12 .2020$

\section{Korespodencija:}

Nikola Savić

Medicinska škola

„Dr Miša Pantić““

Valjevo

Srbija

Tel.: +381645267057

E-mail:

nikolasavicvzs@gmail.com

\section{ORIGINALNI RAD}

\section{INFORMISANOST I LIČNA ISKUSTVA ADOLESCENATA U VEZI SA KONTRACEPCIJOM}

\author{
Nikola SAVIĆ',2, Bojana AVRAMOVIĆ ${ }^{2}$,Zoran JOKIĆ', , Slađana ANĐELIĆ ${ }^{2,4}$, \\ Slobodanka BOGDANOVIĆ VASIĆ
}

${ }^{1}$ Medicinska škola „Dr Miša Pantić“, Valjevo, Srbija; ${ }^{2}$ Fakultet zdravstvenih i poslovnih studija, Univerzitet Singidunum, Valjevo, Srbija; ${ }^{3}$ Poliklinika Jokić, Valjevo, Srbija; ${ }^{4}$ Gradski zavod za hitnu medicinsku pomoć, Beograd, Srbija; ${ }^{5}$ Akademija strukovnih studija, Sabac, Srbija

\begin{abstract}
SAŽETAK
Uvod/cilj Kontracepcija predstavlja najpovoljniju metodu u planiranju porodice. Sprečavanje neželjene trudnoće je značajno, kako sa aspekta očuvanja zdravlja, tako i sa aspekta šireg preventivnog i socijalnog značaja. Cilj rada je ispitati informisanost i lična iskustva adolescenata u vezi sa kontracepcijom.

Metode Istraživanje je sprovedeno u vidu studije preseka. Kao instrument istraživanja, konstruisan je upitnik za adolescente, kojim se procenjuje njihov stepen informisanosti o značaju kontracepcije, kao i lična iskustva. Ispitivanjem je obuhvaćen uzorak od 120 studenata, uzorak je hotimičan, studija je sprovedena na Fakultetu zdravstvenih i poslovnih studija u Valjevu, Univerzitet Singidunum, u vremenskom periodu april-maj 2019. godine. Učešće u studiji je bilo dobrovoljno i anonimno, istraživanje je odobreno od nadležnih organa ustanove.

Rezultati U analizi rezultata korišćene su metode deskriptivne statistike. Ispitanici u posmatranom uzorku su bili starosti od 19 do 23 godine, $83 \%$ ispitanika je ženskog a $17 \%$ muškog pola. Najveći broj ispitanika je informisan o metodama mehaničke kontracepcije i upotrebi prezervativa. Najčešće korišćeno kontraceptivno sredstvo u toku seksualnog odnosa je kondom ili prezervativ (63\%). Veliki broj ispitanika (40\%) smatra da adolescenti treba da budu više informisani o ovoj temi.

Zaključak Rezultati istraživanja ukazuju na potrebu većeg stepena edukacije o metodama i značaju kontracepcije. Neophodno je intenzivirati zdravstveno vaspitni rad, u saradnji sa zdravstvenim ustanovama, školama, visokoškolskim ustanovama i celokupnom zajednicom. Ovu potrebu osećaju i adolescenti, koji smatraju da njihovi vršnjaci ne znaju dovoljno o kontracepciji.
\end{abstract}

Ključne reči Kontracepcija, reproduktivno zdravlje, planiranje porodice, adolescencija.

\section{UVOD}

Kontracepcija je metod izbora u planiranju porodice, ali iako najopravdaniji, nije uvek i najzastupljeniji postupak kontrole rađanja. Razvijene zemlje imaju nekoliko puta višu stopu primene kontracepcije. Neinformisanost, nezaposlenost, materijalne i druge socijalne nepogodnosti, samo su neki od uzroka neprimenjivanja kontracepcije [1].

Reproduktivno zdravlje adolescenata, u velikoj meri zavisi od njihove informisanosti o značaju redovne i pravilne primene kontracepcije.

\section{CILJ RADA}

Cilj rada je ispitati informisanost i lična iskustva adolescenata $u$ vezi sa kontracepcijom.

\section{METOD RADA}

Istraživanje je sprovedeno $\mathrm{u}$ vidu studije preseka. Kao instrument istraživanja, konstruisan je upitnik za adolescente (prilog 1), kojim se procenjuje njihov stepen informisanosti o značaju i primeni kontracepcije.

Ispitivanjem je obuhvaćen uzorak od 120 studenata. Studija je sprovedena na Fakultetu zdravstvenih i poslovnih studija Valjevo, Univerzitet Singidunum, u vremenskom periodu april-maj 2019. godine. Uzorak ispitanika uključenih u istraživačku studiju je hotimičan, a u posmatranom uzorku su bili studenti Zdravstvenog i Poslovnog departmana fakulteta.

Učešće u studiji je bilo dobrovoljno i anonimno. Istraživanje je odobreno od nadležnih organa ustanove.

Kriterijum za uključivanje ispitanika u studiji, je lična saglasnost za učešće u sprovođenju istraživanja, i pristanak da daju odgovor na sva pitanja iz upitnika. Kriterijum za neuključivanje studenata je da nisu želeli da učestvuju u istraživanju. Kriterijum za isključivanje ispitanika iz istraživanja je, želja adolescenata da ne odgovore na sva pitanja iz upitnika.

Pre početka istraživanja ispitanici su dobili potrebne informacije u vezi sa samom studijom u usmenoj i pismenoj formi. Studentima su data uputstva u vezi sa 
pravilnim popunjavanjem upitnika. Distribuciju upitnika, i prikupljanje podataka sprovodili su istraživači lično. Naučni časopis urgentne medicine HALO 194. 2020; 26(3)

Statistička obrada podataka obuhvata metode deskriptivne statistike.

Dobijeni rezultati, predstavljeni su u

apsolutnim brojevima i procentima.

Prilog 1. Anketni upitnik

Poštovani, pred Vama se nalazi anketni upitnik kojim želimo da ispitamo Vaša znanja, stavove i navike vezane za upotrebu kontraceptivnih sredstava. Anketa je anonimna i dobijeni rezultati biće korišćeni isključivo u istraživačke svrhe. Hvala na saradnji!

1. Pol? Muško Žensko

2. Koliko imate godina?

3. Mesto stanovanja? Grad

4. Obrazovni nivo majke

5. Obrazovni nivo oca

6. Kako bi opisali model vaspitanja koji su Vaši roditelji primenjivali? Liberalan / tolerantan Konzervativan / tradicionalan

7. Da li ste do sada prisustvovali edukacijama na temu kontracepcije?

Da Ne

8. Koje metode kontracepcije su Vam poznate?

9. Da li smatrate da ste dovoljno informisani o kontracepciji?

10. Korišćenjem muškog kondoma moguće je sprečiti brojne polno prenosive bolesti i neželjenu trudnoću? Da Ne

11. Da li postoji ženski kondom?

12. Prekinut polni odnos smatra se pouzdanom metodom kontracepcije?

13. Redovna hormonska kontracepcija za žene, koristi se isključivo uz konsultaciju sa ginekologom?

Da Ne

14. Da li postoji muška hormonska kontracepcija?

15. Da li je urgentna hormonska kontracepcija / pilula za jutro posle, metoda redovne kontracepcije?

16. Da li se kontraceptivni učinak povećava kombinacijom više vrsta kontracepcije istovremeno?

17. Da li ste stupili u seksualne odnose?

18. Da li u toku seksualnog odnosa redovno koristite kontracepciju?

Da, redovno Ne koristim redovno Ne koristim kada sam u vezi Samo za neplanirane seksualne odnose

19. Koju metodu kontracepcije koristite?

Kondom ili prezervativ Hormonsku kontracepciju Prekinut polni odnos Ne koristim kontracepciju

20. Kako ste doneli odluku koju kontraceptivnu metodu ćete koristiti? Samostalno Uz konsultaciju sa lekarom

21. O metodama kontracepcije informišem se?

Od strane izabranog lekara/ginekologa U razgovoru sa prijateljima Putem interneta U razgovoru sa roditeljima

22. Da li ste koristili urgentnu kontracepciju, pilulu za jutro posle?

23. Čija je odgovornost kontracepcija? Žene Muškarca partnera

24. Da li smatrate da adolescenti generalno treba da poseduju više informacija o kontracepciji? Ne Na Ne

\section{REZULTATI}

$\mathrm{U}$ ispitivanom uzorku, dominantno je zastupljena ženska populacija (83\%). Najveći broj ispitanika uključenih u studiju dolazi iz gradske sredine (58\%). Iako je najzastupljeniji obrazovni nivo oba roditelja srednja škola, u analiziranom uzorku veliki je procenat roditelja sa osnovnim obrazovanjem. Najveći broj ispitanika (92\%) navodi da su roditelji primenjivali tradicionalan i konzervativan način vaspitanja, što se dovodi u vezu sa niskom stopom adolescenata koji su informacije o kontracepciji tražili ili podelili sa svojim roditeljima (7\%). Najveći broj studenata $(57 \%)$ je prisustvovalo nekom od oblika zdravstvene edukacije na temu kontracepcije (57\%). Najvažnije sociodemografske karakteristike ispitanika u posmatranom uzorku, prikazane su u tabeli 1.

Tabela 2 ilustruje informisanost adolescenata o kontracepciji. Svi adolescenti su prepoznali prezervativ ili kondom kao kontraceptivno sredstvo. Petina ispitanika nije informisana o ženskom kondomu, veliki broj ispitanika $(95 \%)$ nije informisan da postoji i muška hormonska kontracepcija, dok 19\% nije informisano da pilula za jutro posle ne bi trebalo da bude redovna metoda kontracepcije. Svi ispitanici su informisani da se kontraceptivni učinak povećava kombinacijom više metoda. 
Tabela 1. Sociodemografska struktura ispitanika

\begin{tabular}{|c|c|c|c|}
\hline \multicolumn{2}{|c|}{ Kriterijum distribucije ispitanika } & $\mathbf{N}$ & $\%$ \\
\hline \multirow[t]{2}{*}{ Pol } & Muški & 20 & $17 \%$ \\
\hline & Ženski & 100 & $83 \%$ \\
\hline \multirow[t]{5}{*}{ Godine starosti } & 19 & 37 & $31 \%$ \\
\hline & 20 & 32 & $26 \%$ \\
\hline & 21 & 12 & $10 \%$ \\
\hline & 22 & 14 & $12 \%$ \\
\hline & 23 & 25 & $21 \%$ \\
\hline \multirow[t]{2}{*}{ Mesto stanovanja } & Gradska sredina & 70 & $58 \%$ \\
\hline & Seoska sredina & 50 & $42 \%$ \\
\hline \multirow[t]{3}{*}{ Obrazovni nivo majke } & Osnovna škola & 17 & $14 \%$ \\
\hline & Srednja škola & 68 & $62 \%$ \\
\hline & Visoka škola / Fakultet & 17 & $14 \%$ \\
\hline \multirow[t]{3}{*}{ Obrazovni nivo oca } & Osnovna škola & & $8 \%$ \\
\hline & Srednja škola & & $74 \%$ \\
\hline & Visoka škola / Fakultet & & $18 \%$ \\
\hline \multirow{2}{*}{$\begin{array}{l}\text { Kako bi opisali obrazac vaspitanja } \\
\text { koji su primenjivali Vaši roditelji? }\end{array}$} & Tradicionalan / konzervativan & 110 & $92 \%$ \\
\hline & Libaeralan / tolerantan & 10 & $8 \%$ \\
\hline \multirow{2}{*}{$\begin{array}{l}\text { Da li ste do sada prisustvovali } \\
\text { zdravstveno vaspitnim } \\
\text { predavanjima na temu } \\
\text { kontracepcije? }\end{array}$} & $\mathrm{Da}$ & 68 & $57 \%$ \\
\hline & $\mathrm{Ne}$ & 52 & $43 \%$ \\
\hline
\end{tabular}

Tabela 2. Informisanost adolescenata o kontracepciji

\begin{tabular}{|c|c|c|c|}
\hline \multicolumn{2}{|c|}{ Kriterijum distribucije ispitanika } & $\mathbf{N}$ & $\%$ \\
\hline \multirow{4}{*}{$\begin{array}{l}\text { Za koje metode kontracepcije ste } \\
\text { čuli? }\end{array}$} & Kondom / prezervativ & 120 & $100 \%$ \\
\hline & Spirala & 92 & $77 \%$ \\
\hline & $\begin{array}{lll}\text { Urgentna } & \text { kontracepcija/Pilula } \\
\text { jutro posle }\end{array}$ & 109 & $91 \%$ \\
\hline & Oralna hormonska kontracepcija & 118 & $98 \%$ \\
\hline \multirow{2}{*}{$\begin{array}{l}\text { Da li smatrate da ste dovoljno } \\
\text { informisani o primeni } \\
\text { kontracepcije? }\end{array}$} & $\mathrm{Da}$ & 106 & $88 \%$ \\
\hline & $\mathrm{Ne}$ & 14 & $12 \%$ \\
\hline \multirow{2}{*}{$\begin{array}{l}\text { Korišćenjem muškog kondoma } \\
\text { moguće je sprečiti brojne polno } \\
\text { prenosive bolesti i neželjenu } \\
\text { trudnoću? }\end{array}$} & $\mathrm{Da}$ & 120 & $100 \%$ \\
\hline & $\mathrm{Ne}$ & 0 & $0 \%$ \\
\hline \multirow[t]{2}{*}{ Da li postoji ženski kondom? } & $\mathrm{Da}$ & 96 & $80 \%$ \\
\hline & $\mathrm{Ne}$ & 24 & $20 \%$ \\
\hline \multirow{3}{*}{$\begin{array}{l}\text { Prekinut polni odnos smatra se } \\
\text { pouzdanom metodom } \\
\text { kontracepcije? }\end{array}$} & $\mathrm{Da}$ & 10 & $8 \%$ \\
\hline & $\mathrm{Ne}$ & 109 & $91 \%$ \\
\hline & Ne znam & 1 & $1 \%$ \\
\hline \multirow{2}{*}{$\begin{array}{l}\text { Redovna hormonska kontracepcija } \\
\text { za žene, koristi se isključivo uz } \\
\text { konsultaciju sa ginekologom? }\end{array}$} & $\mathrm{Da}$ & 116 & $97 \%$ \\
\hline & $\mathrm{Ne}$ & 4 & $3 \%$ \\
\hline \multirow{2}{*}{$\begin{array}{l}\text { Da li postoji muška hormonska } \\
\text { kontracepcija? }\end{array}$} & $\mathrm{Da}$ & 6 & $5 \%$ \\
\hline & $\mathrm{Ne}$ & 114 & $95 \%$ \\
\hline \multirow{2}{*}{$\begin{array}{l}\text { Da li je urgentna hormonska } \\
\text { kontracepcija / pilula za jutro posle, } \\
\text { metoda redovne kontracepcije? }\end{array}$} & $\mathrm{Da}$ & 23 & $19 \%$ \\
\hline & $\mathrm{Ne}$ & 97 & $81 \%$ \\
\hline \multirow{2}{*}{$\begin{array}{l}\text { Da li se kontraceptivni učinak } \\
\text { povećava kombinacijom više vrsta } \\
\text { kontracepcije istovremeno? }\end{array}$} & $\mathrm{Da}$ & 120 & $100 \%$ \\
\hline & $\mathrm{Ne}$ & 0 & $0 \%$ \\
\hline
\end{tabular}


Analizom ličnih iskustava adolescenata (tabela 3), iako su svi ispitanici u posmatranom uzorku stupili u seksualne odnose, svega $67 \%$ njih redovno koristi kontracepciju, s tim da se najčešće koristi muški kondom ili prezervativ (85\%). Odluka o metodi kontracepcije je najčešće doneta samostalno ( $81 \%)$, bez konsultacije sa stručnim licima. Najveći broj adolescenata, informacije o kontracepciji dobija putem interneta (48\%), iz nerelevantnih izvora podataka. Dvadeset procenata ispitanica je koristilo pilulu za jutro posle, ili urgentnu hormonsku kontracepciju. Najveći broj ispitanika (80\%) slaže se sa ponuđenom tvrdnjom, da je odgovornost vezana za kontracepciju podjednaka u slučaju oba partnera. Svi ispitanici su saglasni da njihovi vršnjaci treba da budu više informisani o značaju redovne kontracepcije.

Tabela 3. Lična iskustva adolescenata u vezi sa kontracepcijom

\begin{tabular}{|c|c|c|c|}
\hline \multicolumn{2}{|c|}{ Kriterijum distribucije ispitanika } & \multirow{2}{*}{$\begin{array}{c}\mathbf{N} \\
120\end{array}$} & \multirow{2}{*}{$\begin{array}{c}\% \\
100 \%\end{array}$} \\
\hline Da li ste stupili u seksualne & $\mathrm{Da}$ & & \\
\hline odnose? & $\mathrm{Ne}$ & 0 & $0 \%$ \\
\hline \multirow{4}{*}{$\begin{array}{l}\text { Da li u toku seksualnog odnosa } \\
\text { redovno koristite kontracepciju? }\end{array}$} & Da, redovno & 80 & $67 \%$ \\
\hline & Ne koristim redovno & 28 & $23 \%$ \\
\hline & Ne koristim kada sam u vezi & 8 & $7 \%$ \\
\hline & Samo za neplanirane seksualne odnose & 4 & $3 \%$ \\
\hline \multirow{3}{*}{$\begin{array}{l}\text { Koju metodu kontracepcije } \\
\text { koristite? }\end{array}$} & Kondom ili prezervativ & 102 & $85 \%$ \\
\hline & Hormonsku kontracepciju & 10 & $8 \%$ \\
\hline & $\begin{array}{l}\text { Prekinut polni odnos / Ne koristim } \\
\text { kontracepciju }\end{array}$ & 8 & $7 \%$ \\
\hline \multirow{2}{*}{$\begin{array}{l}\text { Kako ste doneli odluku koju } \\
\text { kontraceptivnu metodu ćete } \\
\text { koristiti? }\end{array}$} & Samostalno & 97 & $81 \%$ \\
\hline & Uz konsultaciju sa lekarom & 23 & $19 \%$ \\
\hline \multirow{4}{*}{$\begin{array}{l}\text { O metodama kontracepcije } \\
\text { informišem se? }\end{array}$} & Izabrani lekar / ginekolog & 23 & $19 \%$ \\
\hline & U razgovoru sa prijateljima & 31 & $26 \%$ \\
\hline & Putem interneta & 58 & $48 \%$ \\
\hline & U razgovoru sa roditeljima & 8 & $7 \%$ \\
\hline \multirow{2}{*}{$\begin{array}{l}\text { Da li ste koristili urgentnu } \\
\text { kontracepciju, pilulu za jutro } \\
\text { posle? }\end{array}$} & $\mathrm{Da}$ & 24 & $20 \%$ \\
\hline & $\mathrm{Ne}$ & 96 & $80 \%$ \\
\hline \multirow{3}{*}{$\begin{array}{l}\text { Čija je odgovornost } \\
\text { kontracepcija? }\end{array}$} & Ženska & 16 & $13 \%$ \\
\hline & Muška & 8 & $7 \%$ \\
\hline & Oba partnera & 96 & $80 \%$ \\
\hline \multirow{2}{*}{$\begin{array}{l}\text { Da li smatrate da adolescenti } \\
\text { treba da poseduju više } \\
\text { informacija o kontracepciji? }\end{array}$} & $\mathrm{Da}$ & 120 & $100 \%$ \\
\hline & $\mathrm{Ne}$ & 0 & $0 \%$ \\
\hline
\end{tabular}

\section{DISKUSIJA}

Postoje različite vrste kontracepcije, hormonska kontracepcija za žene i muškarce, urgentna hormonska kontracepcija (pilula za jutro posle), intrauterusni ulošci, mehanički kontraceptivi, od kojih se kao i u našoj studiji, najčešće koristi prezervativ ili kondom, spermicidna lokalna sredstva u raznim oblicima [1,2]. Brojne druge metode kontracepcije su trenutno u ispitivanju, kao što su imunokontraceptivne vakcine, kontraceptivne metode za muškarce i unisex kontraceptivi [2].

Nisu sve metode kontracepcije podjednako pouzdane. Neuspeh kontraceptivne metode određuje se brojem žena koje će zatrudneti tokom godinu dana, tokom upotrebe određene metode $\mathrm{u}$ odnosu na 100 korisnica. Ova formula bazirana je na Perlovom indeksu [2]. Kako bi adolescenti bili informisani o značaju i važnosti kontracepcije, potrebno je aktivno vršiti zdravstveno vaspitni rad sa omladinom oba pola, pre svega sa mlađom pupulacijom koja nije stupila $u$ seksualne odnose, i usvojila nerizične obrasce ponašanja. Svi naši ispitanici su već stupili u seksualne kontakte. Prema definiciji Svetske zdravstvene organizacije "Zdravstveno vaspitanje je ne samo širenje informacija o zdravlju, već aktivni proces učenja kroz iskustva" [3]. Mnogi mladi postaju seksualno aktivni u periodu adolescencije. Učestalost rizičnih oblika ponašanja, koji dovode do nekorišćenja metoda kontracepcije i velikog broja namernih prekida trudnoće, kao i širenja polno prenosivih bolesti, kod osoba mlađih od 20 godina, ukazuje na potrebu poboljšanja informisanosti, unapređenju usvajanja pravilnih stavova, i razvijanje veština za odgovorno polno ponašanje adolescenata. Svi naši ispitanici su saglasni sa potrebom bolje informisanosti o kontracepciji. Odgovorno polno 
ponašanje mladih, osnovni je preduslov za očuvanje i unapređenje reproduktivnog zdravlja [4].

Rizično seksualno ponašanje među mlađom populacijom, namerni pobačaji i seksualno prenosive infekcije, uzrokuju neplodnost i smanjenje reproduktivnog potencijala stanovništva. Primarni razlozi za visoku učestalost adolescentnih neželjenih trudnoća, pobačaja i polnih bolesti, u ovoj dobi, leže u nedovoljnoj upotrebi kontracepcije [5]. Jedno od obeležja savremenih društava, je porast seksualne aktivnosti među mladima. Manifestuje se rastućim udelom adolescenata koji su seksualno aktivni, sve većim brojem onih koji prvo polno iskustvo doživljavaju u ranoj adolescenciji (pre 16 godina života), i snižavanjem prosečnog uzrasta kada se prvi polni odnos ostvaruje [6]. Mladi treba da budu informisani o metodama redovne kontracepcije, koja treba da bude što bezbednija i pouzdanija. Urgentna hormonska kontracepcija koristi se samo u izuzetnim slučajevima, nakon pogrešne ili nedosledne upotrebe redovne kontracepcije [7].

Hitna kontracepcija sprečava ili odlaže ovulaciju, sprečava oplodnju i može uticati na implantaciju, ali ne remeti već ustanovljenu trudnoću. U našoj zemlji se na tržištu nalaze dva preparata: levonorgestrel, sa vremenskim rokom za primenu tablete do 72 sata $\mathrm{i}$ ulipristal acetat, sa vremenskim rokom za primenu tablete do 120 sati [8].

Mehanička kontracepcija kao što je prezervativ, štiti ženu od neželjene trudnoće, ali i ženu i muškarca od polno prenosivih bolesti. Veliki broj mladih žena se oslanja na tradicionalne oblike kontracepcije ("coitus interruptus"). Izbor metode kontracepcije je najčešće svojevoljan, bez konsultacije sa lekarom ili drugim zdravstvenim radnicima. Ispravan stav prema kontracepciji i znanje o kontraceptivnim metodama i reprodukciji, stečeni tokom adolescencije preduslovi su odgovornog polnog ponašanja u odraslom dobu [9]. Na korišćenje kontracepcije u adolescentnom dobu utiču brojne varijable, grupa socio-demografskih faktora koji utiču na primenu kontracepcije pre svega, skoro ekskluzivno, dominantni su u zemljama u razvoju, dok se psihološke varijable kao faktor (ne)upotrebe kontracepcije najčešće sreću u razvijenim zemljama [10]. $\mathrm{Na}$ korišćenje kontracepcije u velikoj meri utiče obrazovni nivo osobe. Adolescenti se često informišu putem interneta $\mathrm{i}$ iz nerelevantnih izvora informacija. Komunikacija pedijatara i drugih članova zdravstvenog tima, sa adolescentima i njihovim porodicama, omogućava pružanje pomoći i promovisanje zdravog seksualnog ponašanja, uključujući apstinenciju i pravilnu upotrebu kontracepcije [11]. Iako upotreba kontracepcije uvek treba da bude pod kontrolom lekara i stručnih lica, jer neželjena dejstva određenih vrsta kontracepcije mogu uticati na kvalitet života adolescenta [12], naši ispitanici su najčešće samostalno donosili odluku o izboru kontraceptivnog sredstva. U zdravstveno vaspitni rad treba uključiti i farmaceute, jer brojna kontraceptivna sredstva mogu se kupiti bez lekarskog recepta ili izveštaja, te njihov savet mladima može biti od fundamentalnog značaja $[13,14]$.

Informisanost adolescenata o kontracepciji treba da bude veća, a zdravstveno vaspitni rad pažljivo osmišljen, prilagođen i intenziviran. Rezultate sprovedene studije potvrđuju i druga istraživanja u našoj zemlji. Studenti Univerziteta u Nišu, odluku o primeni kontracepcije takođe donose samostalno, bez konsultacije sa zdravstvenim radnicima (93\%) [15]. U istraživanju sprovedenom na Medicinskom fakultetu, Univerziteta $\mathrm{u}$ Kragujevcu, došlo se do sličnih rezultata: $81,6 \%$ ispitanika koristi kondom kao kontraceptivno sredstvo, dok je više od polovine ispitanika $(53,7 \%)$ nedosledno $u$ primeni kontracepcije [16].

\section{ZAKLJUČAK}

Zdravstveno vaspitni rad u cilju očuvanja i unapređenja reproduktivnog zdravlja mladih, treba da bude uobičajena praksa preventivnih službi, zdravstvenih i obrazovnih institucija. Ciljna grupa na koju je potrebno delovati, kako bi u budućnosti rezultati ovakvih studija bili ohrabrujući, su mlade osobe pre stupanja u seksualne odnose.

Sukob interesa: Autori izjavljuju da ne postoji sukob interesa.

\section{LITERATURA:}

1. Živanović V. Zdravstvena nega u ginekologiji i akušerstvu. Beograd: Visoka zdravstvena škola, 2012. p. 32-50.

2. Đurđević S. Ginekologija. Novi Sad: Univerzitet u Novom Sadu, Medicinski fakultet; 2019, str. 171-189.

3. Jevtić M, Nikolić E. Javno zdravlje za student stomatologije. Novi Sad: Univerzitet u Novom Sadu, Medicinski fakultet; 2011, str. 30-31.

4. Kekuš D. Zdravstveno vaspitanje. Beograd: Autorsko izdanje; 2009, str. 265-267.

5. Hadžimehmedović A, Jahić M, Muratović S. Znanje, stavovi i praksa mladih u Bosni i Hercegovini relevantni za reproduktivno zdravlje. Medicinski pregled. 2017; 70(9-10):289-296.

6. Cvetković A. Reproduktivno zdravlje mladih usmerenost ka zajednici. Opšta medicina. 2016; 22(12):25-35. doi: 10.5937/opmed1601025C.

7. Veljković M, Radulović O, Veličković D. Obaveštenost niških studenata o hitnoj kontracepciji. Acta medica Medianae. 2014; 53(1):15-18. doi: 10.5633/amm.2014.0103.

8. Srećković M, Bogdanović-Vasić S, Karić S, Aleksić U, Banovac M. Procena znanja i stavova studentkinja strukovnih studija za vaspitače o hitnoj kontracepciji, Srbija. Sestrinska reč. 2019;22(79):7-12.

Guzzo K, Hayford S. Adolescent Reproductive and Contraceptive Knowledge and Attitudes and Adult Contraceptive Behavior. Maternal and Child Health Journal. 2018; 22(1): 32-40. PMID: 28755044. doi: 10.1007/s10995-017-2351-7.

9. Bjelica A, Trninić-Pjević A. Pregled identifikovanih faktora koji utiču na upotrebu kontracepcije. Medicinski pregled. 2008; 61(3-4): 151-155. DOI: 10.2298/MPNS0804151B. 
10.Ott M, Sucato G. Contraception for Adolescents. Pediatrics. 2015;134(4):e1257-e1281. PMID: 32041390. doi: 10.4274/jcrpe.galenos.2019.2019.S0003.

11. Wit A, Booij S, Giltay E, Joffe H, Schoevers R, Oldehinkel A. Association of Use of Oral Contraceptives With Depressive Symptoms Among Adolescents and Young Women. JAMA Psychiatry. 2020; 77(1):52. PMID: 31577333.PMCID: PMC6777223 (available on 2020-10-02).

DOI: 10.1001/jamapsychiatry.2019.2838.

12.Turnbull G, Scott R, Mann S, Wellings K. Accessing emergency contraception pills from pharmacies: the experience of young women in London. BMJ Sexual \& Reproductive Health. 2020: 200-339. doi: 10.1136/ bmjsrh-2019-200339.
13.Hsu R, Tavrow P, Uysal J, Alterman A. Seeking the female (internal) condom in retail pharmacies: Experiences of adolescent mystery callers. Contraception. 2020;101(2):117-121. PMID: 31811842. DOI: 10.1016/ j.contraception.2019.10.006.

14.Stanojević M, Stanković L, Selimi A, Kraljević N, Popović I, Popović J. Seksualna aktivnost, upotreba i poznavanje metoda kontracepcije među srednjoškolcima Niša i Preševa. Acta medica Medianae. 2019; 58(3):4048. doi: 10.5633/amm.2019.0306.

15.Mitrašinović $D$, Radovanović $S$, Kocić $S$, Đonović N. Stavovi i ponašanje studenata Medicinskog fakulteta Kragujevac u vezi sa reproduktivnim zdravljem. Materia medica. 2009; 25(1):5-8. 
ORIGINAL ARTICLE

\title{
PERSONAL EXPERIENCE AND HOW INFORMED ADOLESCENTS ARE REGARDING CONTRACEPTION
}

\author{
Nikola SAVIĆ', , Bojana AVRAMOVIĆ ${ }^{2}$,Zoran JOKIĆ ${ }^{2,3}$, Slađana ANĐELIĆ ${ }^{2,4}$, Slobodanka BOGDANOVIĆ \\ VASIĆ \\ ${ }^{1}$ Medical school „Dr Miša Pantic““, Valjevo, Serbia; ${ }^{2}$ Faculty of Health and Business studies, Singidunum \\ University, Valjevo, Serbia; ${ }^{3}$ Polyclinic Jokić, Valjevo, Serbia; ${ }^{4}$ City Institute for Emergency Medical Aid, \\ Belgrade, Serbia; ${ }^{5}$ Academy of Vocational studies, Šabac, Serbia
}

\begin{abstract}
Introduction Contraception is the most favourable method of family planning. Prevention of unwanted pregnancy has great significance, both as a measure of health preservation and as a wider preventive and social measure.

Objective To evaluate how informed the adolescents are when it comes to contraception, as well as to evaluate their personal experiences.

Methods The research was conducted in the form of a cross-sectional study. The research instrument was a questionnaire the adolescents were asked to fill, which contained questions constructed to assess how well they were informed about the importance of contraception as well as their personal experiences. The study included 120 students and the sample was intentional, as the study was conducted at the Faculty of Health and Business Studies in Valjevo, Singidunum University in April-May 2019. The participation in the study was voluntary and anonymous, and the research was approved by the authorities of the institution.

Results The results were analysed using descriptive statistical methods. The respondents were between 19 and 23 years of age and predominantly female $(83 \%)$, while only $17 \%$ were male. The majority of the respondents were well informed on the subject of mechanical contraception methods and the use of condoms. The condom was the most commonly used method of contraception during sexual intercourse (63\%). A large number of respondents $(40 \%)$ believed that adolescents could do with more information on the subject.

Conclusion The research results indicate that there is a need for more education on the subject of the importance and methods of contraception. It is necessary to intensify health education in cooperation with health institutions, schools, higher education institutions and the entire community. This need is felt by the adolescents themselves, who believe that their peers do not know enough about contraception.

Keywords: Contraception, reproductive health, family planning, adolescence.
\end{abstract}

